\title{
Rapid Diagnosis of Soybean Seedling Blight Caused by Rhizoctonia solani and Soybean Charcoal Rot Caused by Macrophomina phaseolina Using LAMP Assays
}

\author{
Chenchen Lu, Bi Song, HaiFeng Zhang, YuanChao Wang, and XiaoBo Zheng
}

Department of Plant Pathology, College of Plant Protection, Nanjing Agricultural University, and Key Laboratory of Integrated Management of Crop Diseases and Pests, Ministry of Education, Nanjing 210095, China.

Accepted for publication 28 August 2015.

\begin{abstract}
Lu, C., Song, B., Zhang, H., Wang, Y., and Zheng, X. 2015. Rapid diagnosis of soybean seedling blight caused by Rhizoctonia solani and soybean charcoal rot caused by Macrophomina phaseolina using LAMP assays. Phytopathology 105:1612-1617.

A new method of direct detection of pathogenic fungi in infected soybean tissues has been reported here. The method rapidly diagnoses soybean seedling blight caused by Rhizoctonia solani and soybean charcoal rot caused by Macrophomina phaseolina, and features loop-mediated isothermal amplification (LAMP). The primers were designed and screened using internal transcribed spacers (ITS) as target DNAs of both pathogens.

An ITS-Rs-LAMP assay for $R$. solani and an ITS-Mp-LAMP assay for M. phaseolina that can detect the pathogen in diseased soybean tissues in the field have been developed. Both LAMP assays efficiently amplified the target genes over $60 \mathrm{~min}$ at $62^{\circ} \mathrm{C}$. A yellow-green color (visible to the naked eye) or intense green fluorescence (visible under ultraviolet light) was only observed in the presence of $R$. solani or M. phaseolina after addition of SYBR Green I. The detection limit of the ITS-Rs-LAMP assay was $10 \mathrm{pg}$ $\mathrm{\mu l}^{-1}$ of genomic DNA; and that of the ITS-Mp-LAMP assay was $100 \mathrm{pg}$ $\mu^{-1}$ of genomic DNA. Using the two assays described here, we successfully and rapidly diagnosed suspect diseased soybean samples collected in the field from Jiangsu and Anhui provinces.
\end{abstract}

Rhizoctonia solani, a widespread fungus that causes a great deal of damage to plants, is a major plant pathogen infecting almost 50 species of important crops ranging from grain and oil crops to fruits and vegetables, including soybean, rice, maize, barley, lettuce, sorghum, and tomato (Kuramae et al. 2003; Vidhyasekaran et al. 1997; Yang et al. 2008). Soybean seedling blight caused by R. solani is an important disease of soybeans, which are commonly grown over broad areas of China (Ren et al. 2001; Prasad and Eizenga 2008; Zhang et al. 2009a; Zhou et al. 2004). Macrophomina phaseolina causes charcoal rot disease on more than 500 plant species worldwide (Dhingra and Sinclair 1978). Agronomically important hosts include soybean, corn, sorghum, and cotton. Work in Missouri during the 1980s showed that the annual loss of soybeans to charcoal rot averaged $5 \%$ statewide, but sometimes attained 30 to $50 \%$ (Wyllie 1988).

$R$. solani and $M$. phaseolina are the major causes of soybean seedling disease (Kunwar et al. 1986; Meyer et al. 1974; Smith and Wyllie 1999; Wrather et al. 2001; Wrather and Koenning 2006). Soybean seedling blight, caused by $R$. solani, and soybean charcoal rot, caused by $M$. phaseolina, are associated with major losses of soybeans (Gangopadhyay et al. 1970; Tachibana 1968). R. solani and $M$. phaseolina principally infect the stem bases of soybean seedlings, and early symptoms are not apparent until the onset of anaphase. After the death of $R$. solani on stems, those stem regions are thinner than healthy regions, and are usually yellowish brown in color. After the death of $M$. phaseolina on stems, the stems do not taper, and are usually dark brown. In late-stage disease, dots visible to the naked eye appear on stem surfaces; these are sclerotia

Corresponding author: X. Zheng; E-mail address: xbzheng@njau.edu.cn

*The $\boldsymbol{e}$-Xtra logo stands for "electronic extra" and indicates that two supplementary figures are published online.

http://dx.doi.org/10.1094/PHYTO-01-15-0023-R

(C) 2015 The American Phytopathological Society produced by the fungi. Seedling diseases caused by $R$. solani and M. phaseolina often occur in Eastern China. Because soil moisture conditions and the cultivation environment vary greatly over such a large region, the causative agents of symptoms are often difficult to identify. Thus, persons who lack adequate field experience cannot easily diagnose the pathogens, especially in the early and middle stages of disease; misdiagnoses are common. New techniques are needed for the rapid diagnosis of seedling blight caused by $R$. solani and charcoal rot caused by M. phaseolina.

At the turn of the century, a more specific, rapid, cost-effective, and easy-to-use method of DNA amplification, termed loopmediated isothermal amplification (LAMP), was designed by Notomi et al. (2000). Compared with polymerase chain reaction (PCR), LAMP does not require a thermal cycler, and four primers recognize six regions of a target gene, affording an amplification efficiency 10- to 1,000-fold greater than that of PCR over a reaction time of less than $80 \mathrm{~min}$. Ready visualization of products renders the technique suitable for rapid diagnosis of disease.

LAMP is easy to perform if suitable primers amplify a target gene. In the present study, internal transcribed spacer (ITS) gene was screened as the target gene and developed an ITS-Rs-LAMP assay for $R$. solani and an ITS-Mp-LAMP assay for M. phaseolina, directly detecting pathogens in diseased host tissues sampled in the field.

\section{MATERIALS AND METHODS}

Strains. $R$. solani and $M$. phaseolina were obtained from diseased soybean seedlings collected in Jiangsu and Anhui provinces (China) in 2014. All tested $R$. solani isolates were isolated by the method of Zhou and Xun from diseased soybean seedlings (Zhou and Yang 1998). The known R. solani isolates isolated from Edamame from Fujian were provided by Q. Chen (Fujian Academy of Agriculture Sciences). All tested M. phaseolina were isolated using the conventional tissue isolation method 
(Zhang et al. 2009b). All of the isolates were identified on the basis of their morphology and ITS sequencing. And eight known strains (CBS140.82, CBS341.36, CBS724.85, CBS970.96, CBS472.82, CBS309.95, CBS324.47, and CBS460.70) were bought from Centraalbureauvoor Schimmelcultures (CBS). The R. solani and $M$. phaseolina isolates, as well as strains of Fusarium spp., Phytophthora sojae, and various other pathogens used in this study, are maintained (Liang 2012) in a collection in the Department of Plant Pathology, Nanjing Agricultural University, China, and are listed in Table 3 .

Culture conditions and DNA extraction. $R$. solani and M. phaseolina were cultured on potato dextrose agar (PDA) medium (200 $\mathrm{g} \mathrm{liter}^{-1}$ of potato extract, $2 \%$ [wt/vol] glucose, and $2 \%$ [wt/vol] agar). Mycelia of each strain and other fungi (except $P$. sojae) were obtained by growing strains in potato dextrose broth ( $200 \mathrm{~g} \mathrm{liter}^{-1}$ of potato extract and $2 \%$ [wt/vol] glucose) at $28^{\circ} \mathrm{C}$ for at least 3 days. $P$. sojae mycelia were grown in V8 juice broth (Zheng 1995). Mycelia were harvested by filtration and frozen at $-20^{\circ} \mathrm{C}$. Mycelial DNA was extracted using DNASecure Plant Kits (Tiangen, Beijing, China) according to the manufacturer's protocol. DNA concentrations were determined spectrophotometrically, compared with commercially obtained standards, and stored at $-20^{\circ} \mathrm{C}$.

LAMP primer design and screening. The ITS regions was chosen as target DNAs. LAMP primers were designed based on the $R$. solani ITS sequence (HG934415.1) and M. phaseolina ITS sequence (AF132795.1). The $R$. solani ITS sequence with those of other related pathogenic fungi in GenBank (Supplementary Fig. S1) were compared. Next, specific primers based on ITS sequence alignments were designed for use in the ITS-Rs-LAMP assay for $R$. solani employing PrimerExplorer V4 software (http:// primerexplorer.jp/e/). The software recommended several primer sets. Primer specificity was tested individually on $R$. solani isolates from different areas, and sets affording positive reactions were selected. Next, primer sensitivities were tested, and primers exhibiting high sensitivity (at least a picogram detection level) were retained. Finally, we tested the primer sets against other fungi (M. phaseolina, Fusarium spp., and other fungal species) and oomycetes, and primers that did not amplify DNA from any other tested organism served as final primers. The primers screened are shown in Table 1. Primers for the ITS-Mp-LAMP assay for $M$. phaseolina were designed and screened in the same manner (Supplementary Fig. S2, Table 2).

LAMP reaction. The final LAMP reaction was performed in a $25-\mu$ l volume, with $0.8 \mu \mathrm{M}$ FIP and BIP, $0.1 \mu \mathrm{M}$ F3 and B3, $0.8 \mathrm{M}$ betaine, $1.4 \mathrm{mM}$ dNTPs, $20 \mathrm{mM}$ Tris- $\mathrm{HCl}$ (pH 8.8), $10 \mathrm{mM} \mathrm{KCl}$, $10 \mathrm{mM}\left(\mathrm{NH}_{4}\right)_{2} \mathrm{SO}_{4}, 6 \mathrm{mM} \mathrm{MgSO} 4,0.1 \%$ (vol/vol) Triton X-100, $8 \mathrm{U}$ of Bst DNA polymerase, and $4 \mu \mathrm{l}$ of target DNA. Reactions were performed in $0.2-\mathrm{ml}$ microtubes in a water bath affording temperature control. Mixtures were incubated at $62^{\circ} \mathrm{C}$ for $60 \mathrm{~min}$ and $0.25 \mu$ of SYBR Green I solution (Sigma-Aldrich, St. Louis,
MO) was then added to each microtube. Positive and negative controls were included in each run, and each sample was analyzed at least three times.

Detection of LAMP products. LAMP products interacting with SYBR Green I were directly visualized by the naked eye and under ultraviolet (UV) light. A positive yellow-green color (to the naked eye) or intense green fluorescence (under UV light) was observed only in the presence of $R$. solani when the ITS-Rs-LAMP assay was run and only in the presence of $M$. phaseolina when the ITS-Mp-LAMP assay was conducted; other strains afforded either no color change or no fluorescence. Such methods were used to confirm that the tests amplified the correct targets.

DNA extraction from diseased soybean tissues after fungal inoculation. Soybean seeds were planted in vermiculite and grown in a greenhouse at $28^{\circ} \mathrm{C}$ until the first true leaves expanded. R. solani and M. phaseolina strains were grown for 3 to 5 days in PDA. Small pieces of cultures $(5 \times 5 \mathrm{~mm})$ were cut from the PDA and then inoculated onto soybean hypocotyls, which were then grown in a greenhouse for 5 days; next, diseased seedling stems were cut (without disinfection) to extract DNA by the method of Wang et al. (1993). Briefly, several milligrams of diseased stem tissue was placed in a $1.5-\mathrm{ml}$ tube and $10 \mu \mathrm{l}$ of $0.5 \mathrm{M} \mathrm{NaOH} / \mathrm{mg}$ of tissue was added. Next, tissues were ground until no large pieces remained. Next, $5 \mu$ l of each suspension was quickly transferred to a new tube containing $495 \mu \mathrm{l}$ of $100 \mathrm{mM}$ Tris ( $\mathrm{pH} 8.0$ ) and mixed; $4 \mu \mathrm{l}$ of this suspension was used in each LAMP reaction. Samples were stored at $-20^{\circ} \mathrm{C}$ if not used immediately. We used the same method to isolate DNA from healthy soybean plants (negative control).

DNA extraction from field-collected diseased tissues. To explore the utilities of the ITS-Rs-LAMP and ITS-Mp-LAMP assays, diseased soybean seedlings were sampled in the field, and DNA was extracted for LAMP assays. Working in Jiangsu and Anhui provinces, we collected samples of suspect soybean seedling blight and soybean charcoal rot and extracted DNAs using DNASecure Plant Kits (Tiangen) according to the manufacturer's instructions. DNA concentrations were determined spectrophotometrically or via quantitation on $1 \%(\mathrm{wt} / \mathrm{vol})$ agarose gels stained with ethidium bromide, compared with commercially obtained standards, and stored at $-20^{\circ} \mathrm{C}$.

\section{RESULTS}

Specificities of the ITS-Rs-LAMP assay and the ITSMp-LAMP assay. The specificities of the LAMP assays were tested using $R$. solani and M. phaseolina, and other fungal strains. Positive or negative results were easily determined upon addition of SYBR Green I. The color of the reaction mixture changed to yellowgreen when amplification was positive, whereas the original orange color was retained when nothing was amplified. Moreover, an intense bright-green fluorescence was observed under UV light

TABLE 1. Primers used for internal transcribed spacers (ITS)/loop-mediated isothermal amplification of Rhizoctonia solani

\begin{tabular}{|c|c|c|c|}
\hline Primer type & Sequence $\left(5^{\prime}-3^{\prime}\right)$ & Length & Target \\
\hline F3 (forward outer) & CGAAATGCGATAAGTAATGTGAA & $23 \mathrm{nt}$ & ITS \\
\hline B3 (backward outer) & AGAGGAGCAGGTGTGAAG & $18 \mathrm{nt}$ & ITS \\
\hline FIP (forward inner) (F1C+F2) & GCTCCAAGGAATACCAAGGAGCCAGAATTCAGTGAATCATCGAATC & 47 mer & ITS \\
\hline
\end{tabular}

TABLE 2. Primers used for internal transcribed spacers (ITS)/loop-mediated isothermal amplification of Macrophomina phaseolina

\begin{tabular}{|c|c|c|c|}
\hline Primer type & Sequence $\left(5^{\prime}-3^{\prime}\right)$ & Length & Target \\
\hline F3 (forward outer) & GCACATTGCGCCCCTTG & $17 \mathrm{nt}$ & ITS \\
\hline B3 (backward outer) & GTTCAGAAGGTTCGTCCGG & $19 \mathrm{nt}$ & ITS \\
\hline FIP (forward inner) $(\mathrm{F} 1 \mathrm{C}+\mathrm{F} 2)$ & AGGACGGTGCCCAATACCAAGCGGGGCATGCCTGTTCGA & 40 mer & ITS \\
\hline
\end{tabular}


after positive amplification, whereas no fluorescence was evident in no-target DNA reactions. As shown in Figure 1A and Table 3, $R$. solani strains, whether isolated from soybeans from Jiangsu or Anhui provinces, or even from edamame from Fujian province, yielded positive reactions, as well as the known strains bought from CBS, whereas other Rhizoctonia spp. and other strains that can cause soybean seedling disease (such as $P$. sojae, Fusarium spp., M. phaseolina, Colletotrichum spp.; Table 3) did not, similar to the negative control (Fig. 1A and B). Other fungal strains were also negative (Fig. 1C). M. phaseolina strains isolated from diseased soybean plants from different areas also yielded positive reactions (Fig. 2A, Table 3), but other pathogenic strains did not, similar to the negative control (Fig. 2B and C). At least three replicates were run to assess the specificities of the LAMP reactions. We found that the ITS-Rs-LAMP and ITS-Mp-LAMP assays species specifically detected $R$. solani and M. phaseolina, respectively.

Sensitivity of the ITS-Rs-LAMP and the ITS-Mp-LAMP assays. Assays were performed using serial tenfold dilutions (100 ng to $10 \mathrm{fg}$ ) of pure $R$. solani and M. phaseolina genomic DNAs to determine the detection limits of the assays employing ITS primers. Decreasing concentrations of DNA were used (left-to-right in Figure 3); the minimum concentration detected in the ITS-Rs-

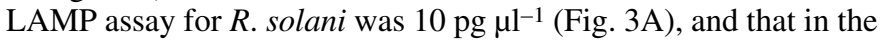

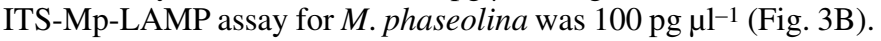

And we complement the quantitative analysis, the minimum concentration detected in the ITS-Rs-LAMP assay for $R$. solani was $2.61 \mathrm{pg} \mu \mathrm{l}^{-1}$, and that in the ITS-Mp-LAMP assay for

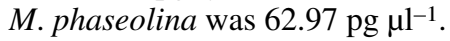

Evaluation of the ITS-Rs-LAMP and the ITS-Mp-LAMP assays in detection of $R$. solani and M. phaseolina in soybeans after inoculation and in diseased soybean tissues from the field. DNAs were extracted from diseased soybean seedling stems infected separately with $R$. solani and $M$. phaseolina to determine if the LAMP assays could detect the pathogens in diseased plants. DNAs were extracted directly from diseased plant tissues to simulate field conditions. As shown in Figure 4A and B, the inoculated tissues yielded positive reactions, similar to the positive controls.

Next, we used the ITS-Rs-LAMP assay to detect $R$. solani and the ITS-Mp-LAMP assay to detect $M$. phaseolina in diseased soybean seedlings collected in the field in Jiangsu and Anhui Provinces. $R$. solani was detected in 33 diseased soybean seedlings from 52 suspect diseased samples in Jiangsu Province, and in 60 diseased soybean plants from 115 suspect diseased samples in Anhui Province. M. phaseolina was detected in 8 diseased soybean plants from 27 suspect diseased samples collected in Jiangsu Province, and in 19 diseased soybean plants from 74 suspect diseased samples in Anhui Province.

Next, $R$. solani and $M$. phaseolina were isolated from diseased soybean plants, which yielded positive reactions. $R$. solani was

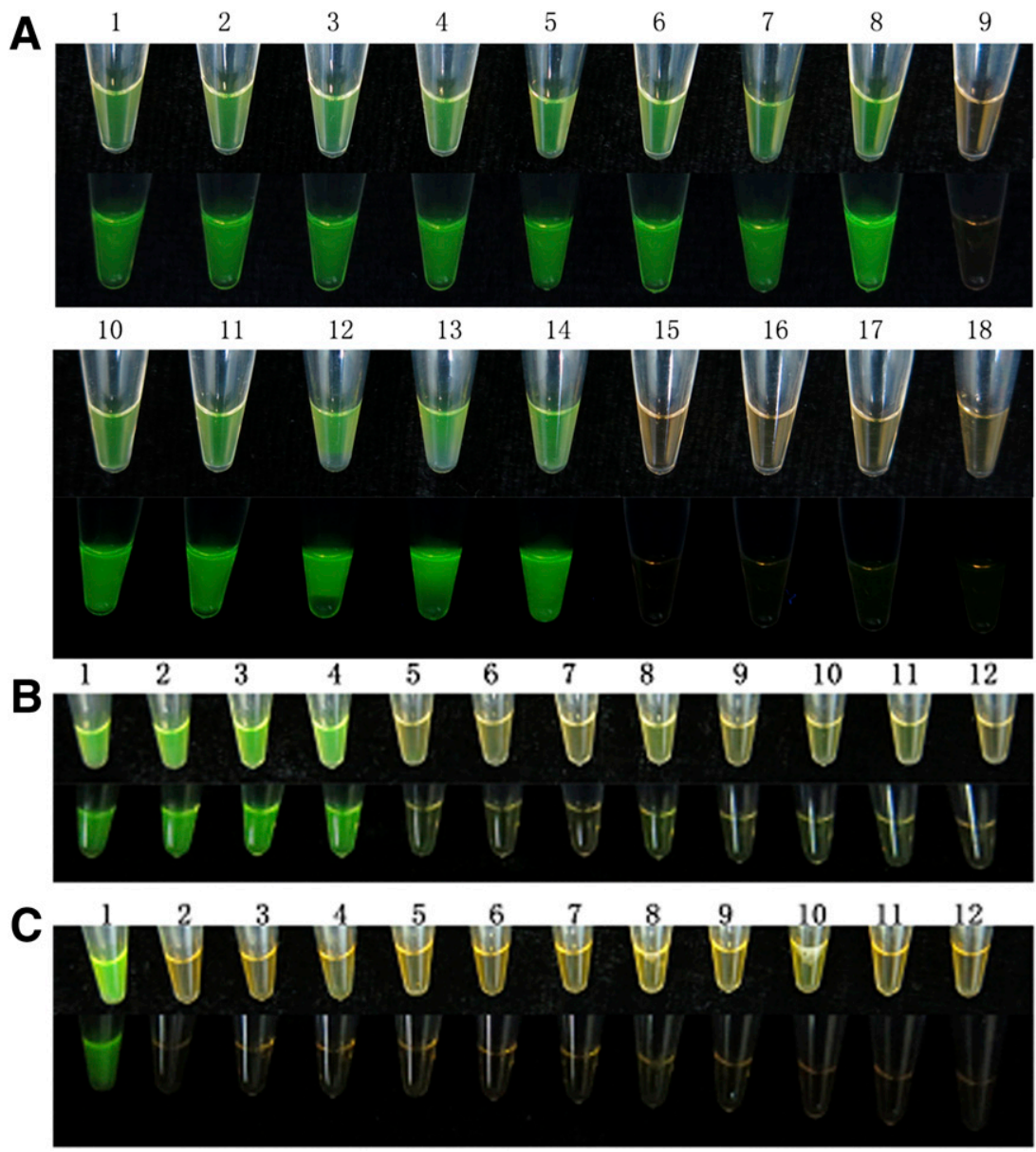

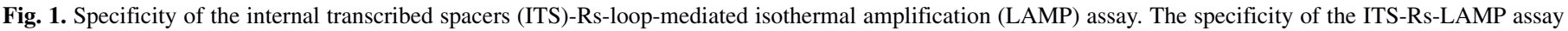

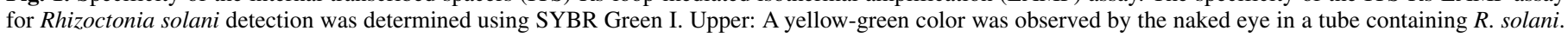

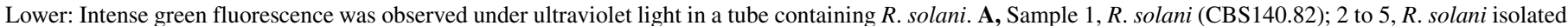

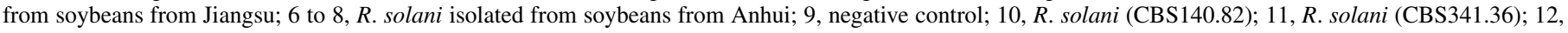

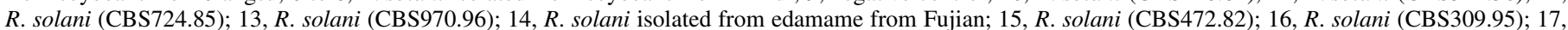

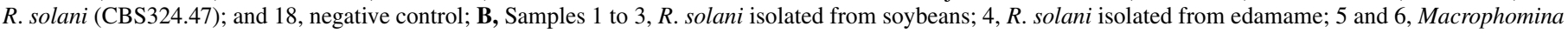

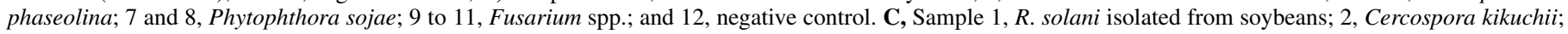

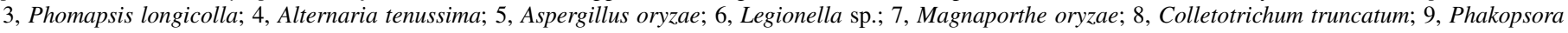
pachyrhizi Sydow; 10, Colletotrichum gloeosporiodes; 11, Nigreospora sphaerica; and 12, negative control. 
TABLE 3. Strains of different fungi used to screen the primer specificity in the study

\begin{tabular}{|c|c|c|c|c|c|}
\hline Species & Host & Source & Number of strain & ITS-Rs-LAMP assay & ITS-Mp-LAMP assay \\
\hline Rhizoctonia solani & Soybean & Jiangpu, Jiangsu & 33 & + & - \\
\hline R. solani & Soybean & Shouguang, Anhui & 28 & + & - \\
\hline R. solani & Soybean & Huaiyuan, Anhui & 32 & + & - \\
\hline R. solani & Edamame & Fujian & 4 & + & - \\
\hline R. solani $(\mathrm{CBS} 140.82)$ & Soybean & Canada & 1 & + & - \\
\hline R. solani (CBS341.36) & Citrus & American & 1 & + & - \\
\hline R. solani (CBS724.85) & Rice & Japan & 1 & + & - \\
\hline R. solani (CBS970.96) & Potato & American & 1 & + & - \\
\hline R. oryzae (CBS472.82) & Rice & American & 1 & + & - \\
\hline R. alpina (CBS309.95) & Viola palustris & Italy & 1 & + & - \\
\hline R. crocorum (CBS324.47) & Phaseolus & Italy & 1 & + & - \\
\hline Macrophomina phaseolina & Soybean & Jiangpu, Jiangsu & 8 & - & + \\
\hline M. phaseolina & Soybean & Huaiyuan, Anhui & 19 & - & + \\
\hline M. phaseolina & Soybean & American & 2 & - & + \\
\hline M. phaseolina (CBS460.70) & Soybean & Denmark & 1 & - & + \\
\hline Fusarium equiseti & Soybean & Jiangsu & 1 & - & - \\
\hline F. graminerum & Soybean & Jiangsu & 1 & - & - \\
\hline F. oxysporum & Soybean & Anhui & 2 & - & - \\
\hline Phytophthora sojae & Soybean & Jiangsu & 1 & - & - \\
\hline Alternaria tenussima & Soybean & ShanDong & 1 & - & - \\
\hline Aspergillus oryzae & Unknown & Unknown & 1 & - & - \\
\hline Cercospora kikuchii & Soybean & Unknown & 1 & - & - \\
\hline Colletotrichum truncatum & Soybean & ShanDong & 1 & - & - \\
\hline C. gloeosporiodes & Soybean & ShanDong & 1 & - & - \\
\hline Legionella sp. & Unknown & Unknown & 1 & - & - \\
\hline Magnaporthe oryzae & Rice & Jiangsu & 1 & - & - \\
\hline Nigreospora sphaerica & Soybean & Sichuan & 1 & - & - \\
\hline Phakopsora pachyrhizi & Soybean & Yunnan & 1 & - & - \\
\hline Phomapsis longicolla & Soybean & Hubei & 1 & - & - \\
\hline
\end{tabular}
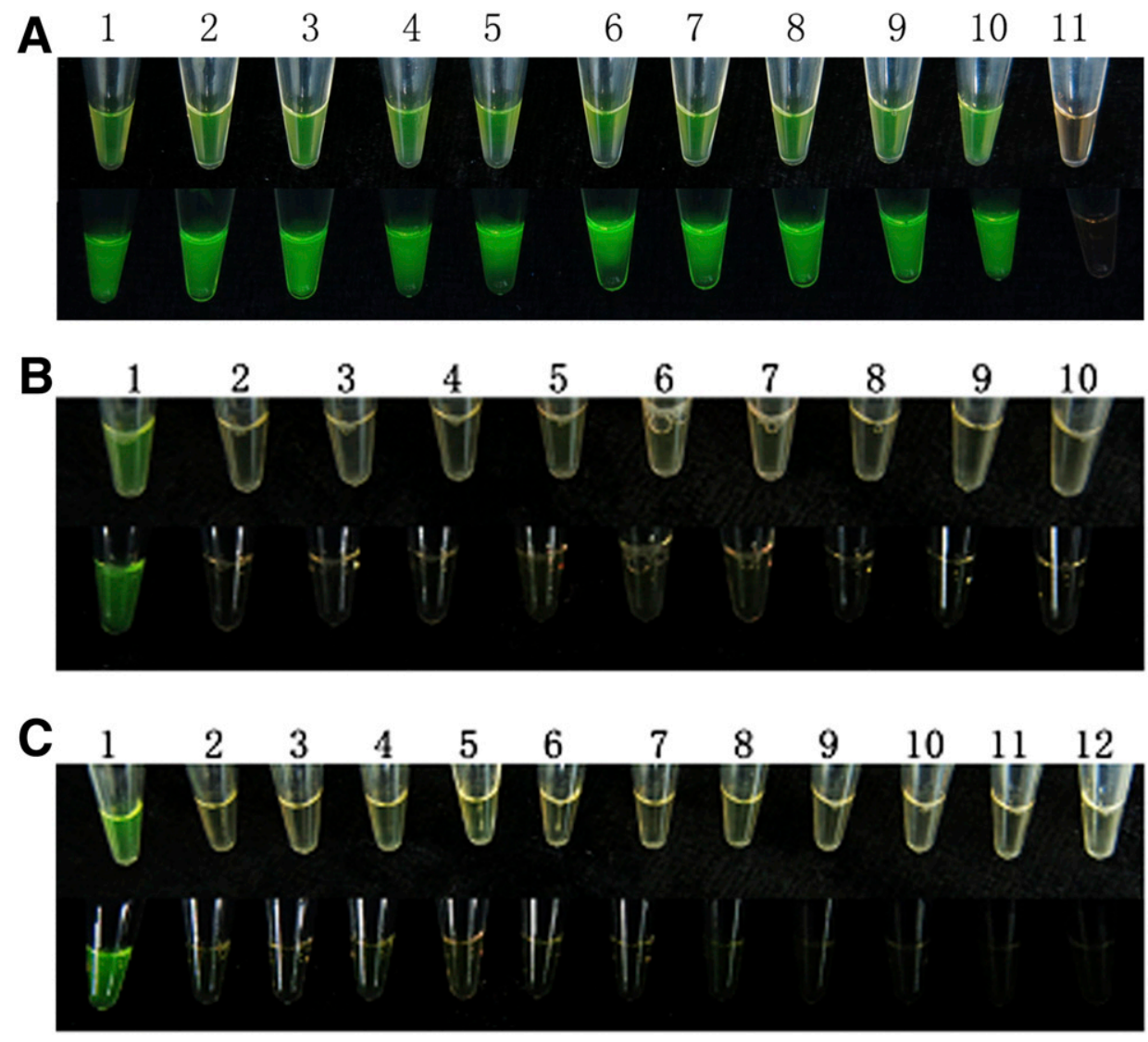

Fig. 2. Specificity of the internal transcribed spacers (ITS)-Mp-loop-mediated isothermal amplification (LAMP) assay. Upper: A yellow-green color was observed by the naked eye in a tube containing Macrophomina phaseolina. Lower: An intense green fluorescence was observed under ultraviolet light in the tube containing M. phaseolina. A, Sample 1, M. phaseolina (CBS460.70); 2 and 3, M. phaseolina isolated from soybeans from American; 4 to 6, M. phaseolina isolated from soybeans from Jiangsu; 7 to 10, M. phaseolina isolated from soybeans from Anhui; and 11, negative control. B, Sample 1, M. phaseolina isolated from soybeans; 2 and 3, R. solani isolated from soybeans; 4 and 5, Phytophthora sojae; 6 to 9, Fusarium spp.; 12, negative control. C, Sample 1, M. phaseolina isolated from soybean; 2, Cercospora kikuchii; 3, Phomapsis longicolla; 4, Alternaria tenussima; 5, Aspergillus oryzae; 6, Legionella sp.; 7, Magnaporthe oryzae; 8, Colletotrichum truncatum; 9, Phakopsora pachyrhizi Sydow; 10, Colletotrichum gloeosporiodes; 11, Nigreospora sphaerica; and 12, negative control. 
isolated 86 from 93 ITS-Rs-LAMP assay-positive samples and M. phaseolina was isolated 23 from 27 ITS-Mp-LAMP assaypositive samples. We finally identified all of the isolates morphologically, and via ITS sequencing, obtained results consistent with the LAMP assay data.

\section{DISCUSSION}

Here the ITS-Rs-LAMP assay for $R$. solani and the ITS-MpLAMP assay for $M$. phaseolina were developed, and showed that the assays directly and rapidly detect $R$. solani or M. phaseolina in diseased soybean tissues from the field. We thus describe a new method for the rapid diagnosis of plant diseases caused by fungi; infected plant tissues may be directly analyzed.

In recent years, many molecular methods for detection of pathogenic fungi have been developed.
However, for practical purposes, tests detecting pathogenic crop fungi must be rapid, should be simple to perform, minimally expensive, and not dependent on expensive equipment. Such tests need to be completed on farms or in agricultural extension stations using relatively simple equipment. DNA probe detection technology and real-time quantitative PCR were not applicable because of expensive and time-intensive. We have developed a rapid diagnostic technique based on the LAMP assay, which does not require expensive equipment. A LAMP reaction can be completed in a thermostatted water bath or a vacuum cup. PCR is often used to detect crop pathogenic fungi because of these advantages. Compared with PCR, however, the LAMP assays described here have the following advantages. (i) High specificity. In the LAMP assay, four primers recognize six regions on a target gene, whereas, in PCR, only two primers bind to two regions on a target gene. (ii) High sensitivity. LAMP assay efficiency is 10 - to 1,000 -fold
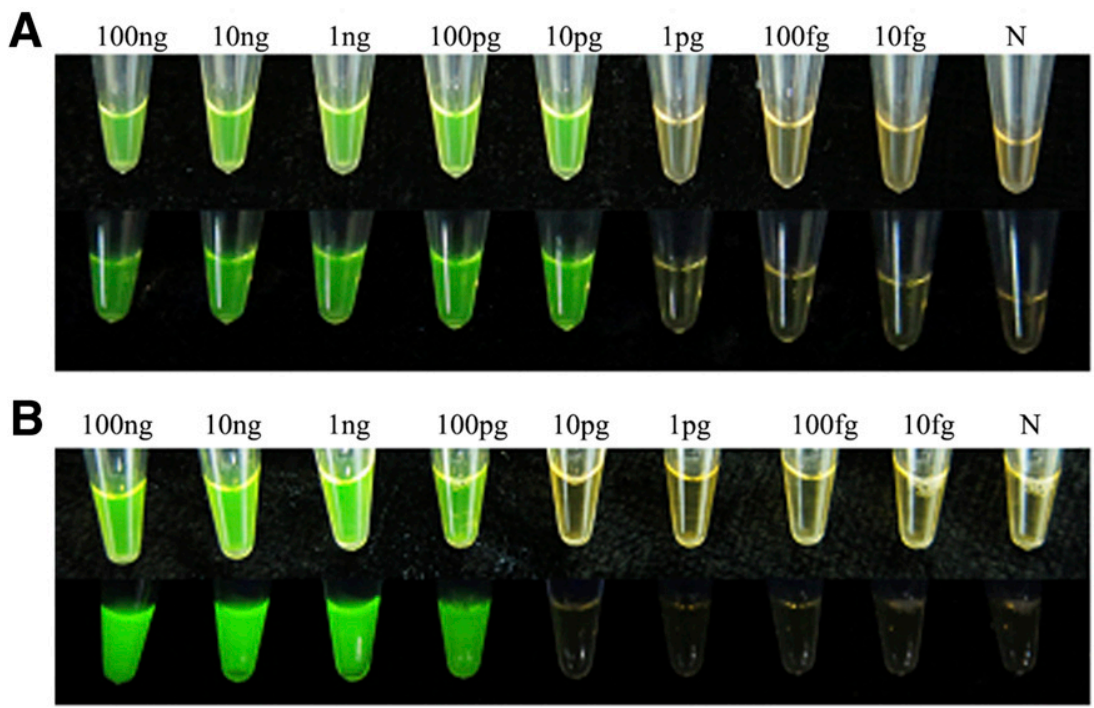

Fig. 3. Sensitivity of the internal transcribed spacers (ITS)-Rs-loop-mediated isothermal amplification (LAMP) assay for Rhizoctonia solani and the ITS-MpLAMP assay for Macrophomina phaseolina. Sensitivity of the ITS-LAMP assays was evaluated using serially diluted genomic DNA (100 ng to $10 \mathrm{fg}$ ) of $R$. solani and M. phaseolina isolates as templates, and $\mathrm{N}$ was the negative control. A, The detection limit of the ITS-Rs-LAMP assay. B, The detection limit of the ITS-MpLAMP assay. The sensitivity of the LAMP method was determined using SYBR Green I. Upper: A positive reaction was indicated by a color change from orange to yellow-green, visible to the naked eye. Lower: Intense green fluorescence was observed under ultraviolet light after a positive amplification.

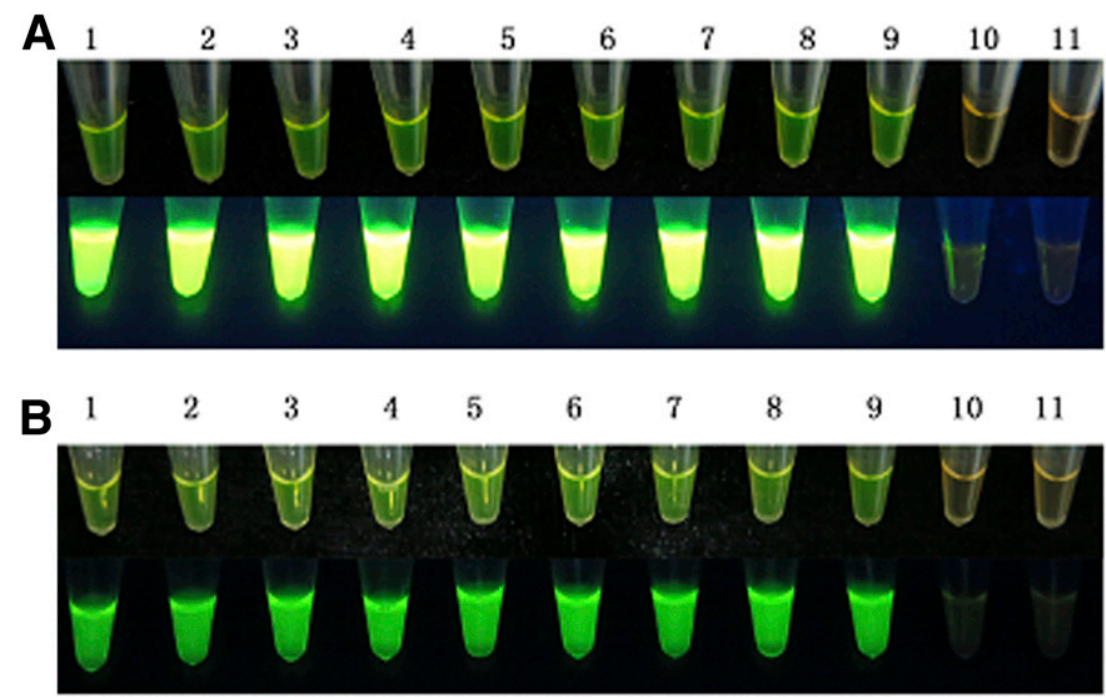

Fig. 4. Evaluation of the internal transcribed spacers (ITS)-Rs-loop-mediated isothermal amplification (LAMP) assay for Rhizoctonia solani and the ITS-MpLAMP assay for Macrophomina phaseolina after inoculation of soybeans. A, Samples 1 to 8, tissues inoculated with an $R$. solani isolate; 9, DNA isolated from $R$. solani; 10, healthy plant tissue; and 11, negative control. B, Samples 1 to 8, tissues inoculated with an M. phaseolina isolate; 9, DNA from an M. phaseolina isolate; 10 , healthy plant tissue; and 11, negative control. 
greater than that of PCR. (iii) Speed. A diagnosis of a pathogenic fungus via a LAMP assay requires about $2 \mathrm{~h}$; PCR needs 6 to $8 \mathrm{~h}$. And (iv) ease of use. The results of a LAMP assay can be directly observed by the naked eye; there is no need to electrophorese amplification products, unlike in PCR.

There are disadvantages of LAMP assays exclusively based on "naked eyes", only qualitative not quantitative. LAMP results can only show the detection ranges of sensitivity. The detection

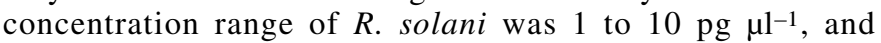

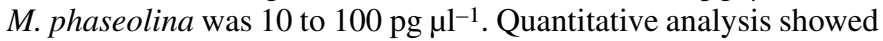

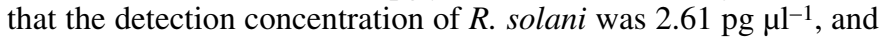
of $M$. phaseolina was $62.97 \mathrm{pg} \mu \mathrm{l}^{-1}$. Both were the same as the detection range of sensitivity of LAMP assay.

In the past, detection of plant-pathogenic fungi usually required isolation of pure fungi from diseased plant tissues. The ITS-RsLAMP and ITS-Mp-LAMP assays described here directly detect $R$. solani or M. phaseolina, respectively, in DNA mixtures extracted from diseased soybean tissues. Such samples contain DNA of the host plant, that of $R$. solani or M. phaseolina, and those of other saprophytic microbes of diseased tissues and soil. Because the assays are both specific and sensitive, they accurately detect $R$. solani or M. phaseolina in DNA mixtures, thus allowing soybean seedling blight caused by $R$. solani or soybean charcoal rot caused by $M$. phaseolina to be reliably detected. And compared with the conventional tissue isolation method, our LAMP assays significantly improved the detection efficiency.

Thus, our ITS-Rs-LAMP assay for $R$. solani and ITS-Mp-LAMP assay for $M$. phaseolina can be used to rapidly diagnose soybean seedling blight and soybean charcoal rot on soybean seedlings, and may facilitate control of such diseases.

\section{ACKNOWLEDGMENTS}

This research was supported by the National High-Tech R\&D Program (863 Program) (grant 2012AA101501), the National Department Public Benefit Research Foundation (grant 200903004), the Chinese National Science Foundation Committee (project 31225022), and the Public Sector Research Funding (grant 201303018).

\section{LITERATURE CITED}

Dhingra, O. D., and Sinclair, J. B. 1978. Biology and Pathology of Macrophomina phaseolina. Imprensa Universitaria, Universidade Federal de Vicosa. Minas Gerais, Brazil.

Gangopadhyay, S., Wyllie, T., and Luedders, V. 1970. Charcoal rot disease of soybean transmitted by seeds. Plant Dis. Rep. 54:1088-1091.
Kunwar, I., Singh, T., Machado, C., and Sinclair, J. 1986. Histopathology of soybean seed and seedling infection by Macrophomina phaseolina. Phytopathology 76:532-535.

Kuramae, E. E., Buzeto, A. L., Ciampi, M. B., and Souza, N. L. 2003. Identification of Rhizoctonia solani AG 1-IB in lettuce, AG 4 HG-I in tomato and melon, and AG 4 HG-III in broccoli and spinach, in Brazil. Eur. J. Plant Pathol. 109:391-395.

Liang, N. 2012. A summary of microbial strain preservation methods. Academic Periodical of Farm Products Processing 277:117-118.

Meyer, W., Sinclair, J., and Khare, M. 1974. Factors affecting charcoal rot of soybean seedlings. Phytopathology 64:845-849.

Notomi, T., Okayama, H., Masubuchi, H., Yonekawa, T., Watanabe, K., Amino, N., and Hase, T. 2000. Loop-mediated isothermal amplification of DNA. Nucleic Acids Res. 28:e63.

Prasad, B., and Eizenga, G. 2008. Rice sheath blight disease resistance identified in Oryza spp. accessions. Plant Dis. 92:1503-1509.

Ren, C., Gao, B., and He, Y. 2001. Advance in rice resistance to rice sheath blight. Plant Prot. 27:32-36.

Smith, G., and Wyllie, T. 1999. Charcoal rot. Pages 29-30 in: Compendium of Soybean Diseases, 4th ed. G. C. Hartman, J. B. Sinclair, and J. C. Rupe, eds. The American Phytopathological Society, St. Paul, MN.

Tachibana, H. 1968. Rhizoctonia solani root rot epidemic of soybeans in Central Iowa 1967. Plant Dis. Rep. 52:613-614.

Vidhyasekaran, P., Ponmalar, T. R., Samiyappan, R., Velazhahan, R., Vimala, R., Ramanathan, A., Paranidharan, V., and Muthukrishnan, S. 1997. Hostspecific toxin production by Rhizoctonia solani, the rice sheath blight pathogen. Phytopathology 87:1258-1263.

Wang, H., Qi, M., and Cutler, A. J. 1993. A simple method of preparing plant samples for PCR. Nucleic Acids Res. 21:4153-4154.

Wrather, J., Anderson, T., Arsyad, D., Tan, Y., Ploper, L. D., Porta-Puglia, A., Ram, H., and Yorinori, J. 2001. Soybean disease loss estimates for the top ten soybean-producing countries in 1998. Can. J. Plant Pathol. 23:115-121.

Wrather, J. A., and Koenning, S. R. 2006. Estimates of disease effects on soybean yields in the United States 2003 to 2005. J. Nematol. 38:173-180.

Wyllie, T. 1988. Charcoal rot of soybeans: Current status. Wisconsin Field Crops Pathology, University of Wisconsin.

Yang, G., Conner, R., Chen, Y., Chen, J., and Wang, Y. 2008. Frequency and pathogenicity distribution of Rhizoctonia spp. causing sheath blight on rice and banded leaf disease on maize in Yunnan, China. J. Plant Pathol. 90:387-392.

Zhang, C., Liu, Y., Ma, X., Feng, Z., and Ma, Z. 2009a. Characterization of sensitivity of Rhizoctonia solani, causing rice sheath blight, to mepronil and boscalid. Crop Prot. 28:381-386.

Zhang, J., Cui, Y., Duan, C., Wu, X., Wang, X., and Zhu, Z. 2009b. Identification of pathogen causing soybean charcoal rot. Acta Agric. BorealiSinica 5:192-196.

Zheng, X. 1995. Methods in Phytophthora. Chinese Agriculture Press, Beijing.

Zhou, E., and Yang, M., 1998. A rapid and simple technique for the isolation of Rhizoctonia solani from diseased plant tissues. J. South China Agric. Univ. 19:125-126.

Zhou, W., Cheng, W., Xu, H., Jiang, Y., Zhou, F., and Qin, L. 2004. The present situation of research and some problems on maize sheath blight. Chinese Agric. Sci. Bull. 21:331-336. 